\title{
HEALTH INFORMATION SEARCH ENGINE THE NEW TOOLS OF HEALTH LITERACY
}

\section{Type of article: conference abstract}

\author{
Zahra ebnehoseini1* \\ 1: Ph.D. Student Medical Informatics, Department of Medical Informatics, School of \\ Medical, University of Medical Sciences, Mashhad, Iran. \\ Tel: +98.09370802011, E-mail: EbnehoseiniZ1@Mums.ac.ir
}

\begin{abstract}
Introduction: Access to Health Information is very essential for promoting health literacy, selfcare, shared decision making, medication adherence. Internet is one of the main resources of health information. Many studies showed the main gateway for seeking health information was search engines. But finding qualitfied health information is a challenge. Therefore, this study aimed to introduce top health Searches engines and review their features.

Methods: According to litreture review 10 health Searches engins were selected. Common features of each search engine, such as the ability to create profiles, the type of health information provided, target users, health information sources contained in the search engine, and the unique feature and other features, were reviewed and the comparison table was provided. A common search scenario was also tested on all search engines and the result of the data retrieval was reported by the search engine.

Results: health Searches engine like that PubMed 'Med scape 'McGraw-Hill Medical ، iMediSearch ‘medicin.net ,Hardin.Md ‘Health line ‘EMedicine ‘Merck and Ovid were chosen and reported.

Conclusion:The results of this study can help users such as patient to choose a valid health searches engine and also help them to find health searches engine appropriate for their health problem and know what features in health website is important.

KEYWORDS: health searches engine, health literacy
\end{abstract}

\section{Declaration of conflicts}

This abstract is selected from the First International Congress of Diseases and Health Outcomes Registry and First National Congress of Medical Informatics, 14-17 February 2017, Mashhad, Iran

\section{Authors' biography}

No biography.

\section{References}

No references. 